\title{
Reactive palladium carbenes: Migratory insertion and other carbene-hydrocarbyl coupling reactions on well-defined systems.
}

\author{
Ana C. Albéniz*[a]
}

\begin{abstract}
Palladium complexes with carbene ligands are among the best known and more extensively used catalysts. Those carbenes are usually $\mathrm{NHC}$ or $\mathrm{N}, \mathrm{N}$ disubstituted derivatives and their use rely on the robust nature of the carbene ligands and their role as auxiliary ligands that modify the metal electronic and steric features. In contrast, there are other types of carbenes that, when coordinated to palladium, lead to transformations where the carbene fragment is involved. In the last decade, palladium-catalyzed reactions have been extended to the use of carbene precursors that can be functionalized with the formation of several $\mathrm{C}-\mathrm{C}$ bonds in one reaction step. Plausible mechanisms have been proposed where a carbene-hydrocarbyl coupling occurs in the palladium coordination sphere. This microreview is intented to collect and discuss the examples of organometallic reactions in well-characterized palladium complexes where the carbene is one of the fragments involved in C$\mathrm{C}$ bond formation. These examples are key in understanding and supporting the mechanisms proposed for the Pd-catalyzed of C-C coupling reactions of carbenes.
\end{abstract}

\section{Introduction}

Palladium catalysis is central in the formation of C-C and Cheteroatom bonds to build up molecular complexity. A large number of processes combine an electrophilic reagent (usually an organic halide) and a nucleophilic one (an organometallic reagent, an amine, alkynyl, alkene, enolate etc.) in the variety of useful classical cross coupling transformations: SuzukiMiyaura, ${ }^{[1]}$ Stille ${ }^{[2]}$ Negishi, ${ }^{[3]}$ Hiyama,${ }^{[4]}$ Kumada ${ }^{[5]}$ BuchwaldHartwig amination, ${ }^{[6]}$ Sonogashira, ${ }^{[7]}$ Heck, ${ }^{[8]}$ and others. ${ }^{[9]}$ Palladium catalytic systems that allow the use of hydrocarbons as one or two of the reaction partners in cross coupling reactions have also been developed. ${ }^{[10]}$ In the last fifteen years, new Pdcatalyzed transformations have been reported where carbene precursor reagents are used in palladium-catalyzed C-C coupling reactions. The carbene is incorporated into the final products and in many cases several C-C or C-X bonds are formed by double functionalization of the carbene fragment. It is proposed that in the course of the catalytic transformation a carbene moiety is transferred to palladium and then, a migratory insertion reaction of the carbene into a preformed $\mathrm{Pd}-\mathrm{R}$ bond occurs, as shown in Scheme 1. A new palladium alkyl complex is formed in this way, which can be converted to the final products through manifold transformations.

[a] Prof. Dr. A. C. Albéniz

IU CINQUIMA/Química Inorgánica

Universidad de Valladolid

47071 Valladolid, Spain

E-mail: albeniz@qi.uva.es

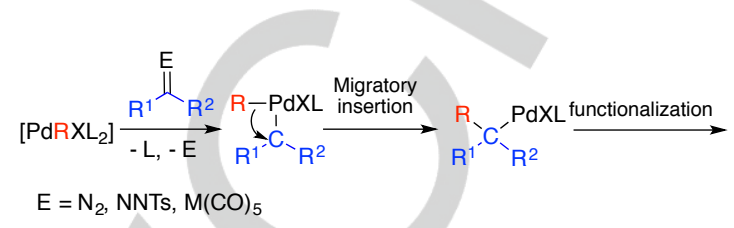

Scheme 1. Formation of a new $\mathrm{C}-\mathrm{C}$ bond and a palladium alkyl complex by carbene transfer and migratory insertion.

Scheme 2 illustrates the variety of reactions that can be carried out. Pioneer work by Van Vranken et al. showed that this process was feasible, ${ }^{[11]}$ and since then, extensive work by the groups of Barluenga and Valdés, ${ }^{[12,13]}$ Wang, ${ }^{[14]}$ Van Vranken, ${ }^{[15]}$ and others, ${ }^{[16]}$ have shown the synthetic power of the coupling processes that combine carbene migratory insertion with other fundamental steps in palladium chemistry.

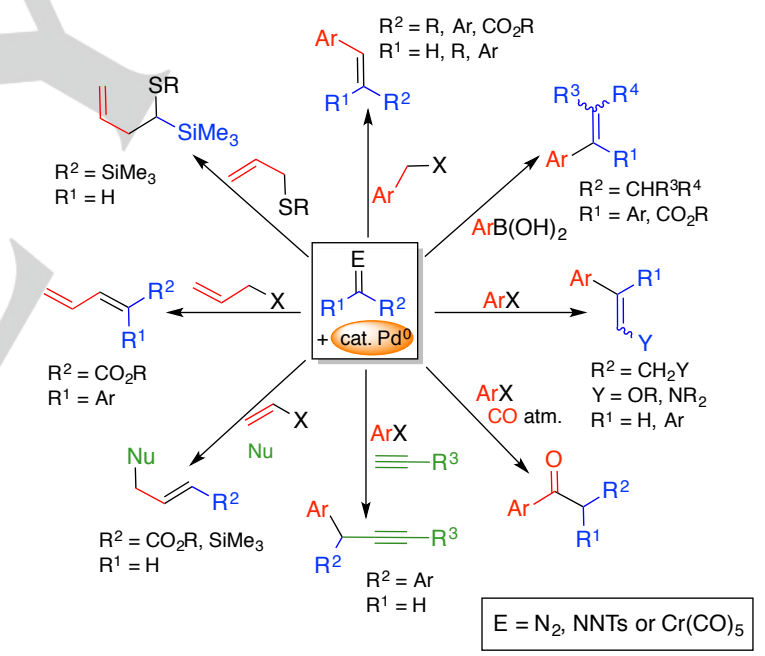

Scheme 2. Some examples of Pd-catalyzed transformations via carbene transfer and carbene migratory insertion.

Many carbene-precursor reagents $\left(E=C R^{1} R^{2}\right.$ in Schemes 1 and 2) can be used to form the palladium carbene complex, ${ }^{[17]}$ including group 6 metal carbenes. ${ }^{[18]}$ Initially, diazoderivatives were the most commonly used carbene precursors and although they are still employed, these derivatives are sometimes difficult to synthesize and to handle. In 2007 Barluenga and Valdés reported the use of sulfonylhydrazones as carbene precursors in palladium catalyzed coupling reactions. ${ }^{[12]}$ The in situ transformation of sulfonylhydrazones to diazoalkanes under basic conditions, the Bamford-Stevens reaction, ${ }^{[19]}$ avoids the handling of the latter derivatives, making the reactions more attractive and extending the range of available carbene fragments for these reactions. ${ }^{[20]}$ As a consequence, the work on this area has experience a surge in the last decade and 
nowadays these reactions have become part of the toolbox of palladium-catalyzed carbon-forming reactions for the synthetic chemist. The topic has been reviewed and profuse and detailed information can be found in the literature, ${ }^{[21]}$ including quite recent accounts. ${ }^{[22]}$

The development of synthetic applications of catalytic reactions involving a carbene migratory insertion step in a palladium complex has been fast and successful. The extension of the catalytic scope has been achieved much faster than the detailed knowledge of the steps proposed in the mechanism of these reactions. New synthetic methodologies have been produced in this way in the past, and this is a valid approach. However, a careful look into the fundamental steps involved in the catalysis has also proved to be necessary to bring a new reaction to its full potential. The experimental study of the migratory insertion reaction, represented in Scheme 1 and invoked as a fundamental step in the catalytic transformations in Scheme 2, is not an easy task. This step is difficult to separate from the steps preceding and following it: A fast migratory insertion reaction occurs on very reactive palladium carbenes, which are difficult to detect or isolate, and leads to a palladium alkyl which can easily decompose, most commonly by $\beta-\mathrm{H}$ elimination. Nonetheless, there are enough precedents and experimental evidence in the literature that show that the carbene migratory insertion reaction occurs in palladium complexes. This microreview intends to collect those examples and what can be learnt form them about the factors that favor this reaction.

The reactivity of palladium carbenes can be strongly modified by changing the nature of the substituents on the carbene carbon. Extremely robust examples as well as very reactive (non-isolable) species belong to this family of complexes. Thus, before discussing the $\mathrm{C}-\mathrm{C}$ bond forming reactions a brief overview of the types of palladium carbene complexes and their electronic features are given in section 2.

By analogy with other well-known reactions such as the migratory insertion of $\mathrm{CO}$ or isonitriles into $\mathrm{Pd}-\mathrm{R}$ bonds, a formal carbene migratory insertion into a $\mathrm{Pd}-\mathrm{R}$ bond should give a new organometallic complex, a Pd-alkyl, in the same way as the insertion of $\mathrm{CO}$ gives an acyl complex or the insertion of RNC leads to an iminoacyl complex. The new palladium alkyl derivative could then undergo a subsequent transformation or functionalization, leading to the final products, as observed in catalytic processes (Scheme 2). With this formal criterion, section 3 shows examples where the carbene- $R$ coupling leads to a new palladium organometallic complex that retains the newly formed moiety. On the other hand, the formation of a carbene- $R(R=$ hydrocarbyl) bond can occur through reactions formally different from a migratory insertion, such as a reductive elimination. The nature of the interaction between the carbene and hydrocarbyl groups in the coordination sphere of the metal may not be that different in both processes and small changes in the transition states lead to a range of situations closer to a concerted reductive elimination or a migratory insertion. In fact, the term "migratory reductive elimination" has been coined to refer to examples of reductive elimination processes not involving carbenes where the transition state shows a migration of one group to the other, rather that a more symmetrical arrangement. ${ }^{[23]}$ However, formally, the process is different since the carbene- $R$ product is eliminated and no further functionalization on the metal can occur. This has been observed mostly for $\mathrm{N}$-heterocyclic carbenes where the coupling product is a stable azolium salt and examples will be discussed in section 4.

Carbene-hydrocarbyl couplings are not the only C-C forming reactions that involve carbene fragments and palladium complexes. For example, palladium carbene intermediates have been proposed in the well known Pd-catalyzed cyclopropanation, ${ }^{[24]}$ as well as in the dimerization of group 6 metal carbenes. ${ }^{[25]}$ Some diazoalkane polymerizations are also catalyzed by palladium complexes. [ 26 ] However, these processes are outside the scope of this microreview and will not be discussed here.

\section{An overview of Palladium(II) carbene complexes}

Migratory insertion reactions in $\left[P d R(\right.$ carbene $\left.) L_{2}\right]$ species require an electrophilic palladium carbene that interacts with the $R$ group acting as a nucleophile. Electrophilicity is not a strange electronic feature for carbene complexes of $\mathrm{Pd}(\mathrm{II})$, where the metal has a very limited $\pi$ back-donation ability, as expected for a late transition metal in oxidation state +2 . The carbene fragment is basically a singlet species acting as a two electron neutral donor ligand ( $\sigma$-interaction, Figure 1). In the absence of electron donor substituents, given the low extent of backdonation from the metal ( $\pi$-interaction, Figure 1$)$, the $\pi$ empty orbital centered on the carbene carbon is available, resulting in very reactive complexes which cannot generally be detected, less isolated. Of course, the electrophilicity of the carbene fragment can be modulated by the substituents of the carbene carbon leading to a wide variation of properties and reactivity. Nonetheless, using the classical classification based on reactivity, $\mathrm{Pd}(\mathrm{II})$ carbenes can be considered electrophillic carbenes, i.e. Fisher type carbenes.
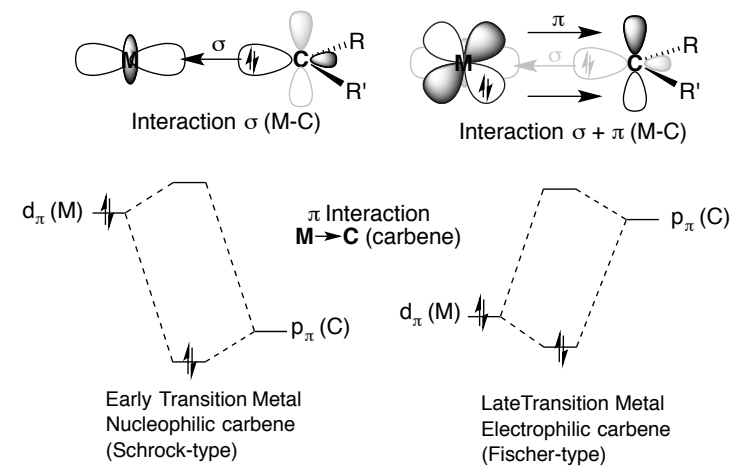

Figure 1. Schematic metal-carbene bonding interactions and the electronic features of a carbene complex depending on the type of transition metal center. 
Figure 2 shows some examples of characterized Pd(II) carbenes, most of them in analogous metal coordination environments, and the ${ }^{13} \mathrm{C}$ NMR resonances for their $\mathrm{C}_{\text {carbene }}{ }^{[27]}$ The chemical shift for this nucleus is sensitive to a variety of factors, including the other ligands coordinated to the metal, but large differences are observed between different types of carbene fragments, that can be clearly related to the electron density on the carbene carbon. Complex 1 shows a very electrophilic $\mathrm{C}(\mathrm{p}-\mathrm{Tol})_{2}$ fragment since the tolyl groups can be considered just as spectator substituents as far as their electron influence on the carbene is concerned, and according to the classification used by Bertrand and Bourissou. ${ }^{[28]}$ Indeed, the value of the ${ }^{13} \mathrm{C}$ NMR resonance for this complex (313.4 ppm) shows a very deshielded carbene carbon and its low reactivity may be a result of its being encumbered by the bulky pincer ligand. ${ }^{[29]}$

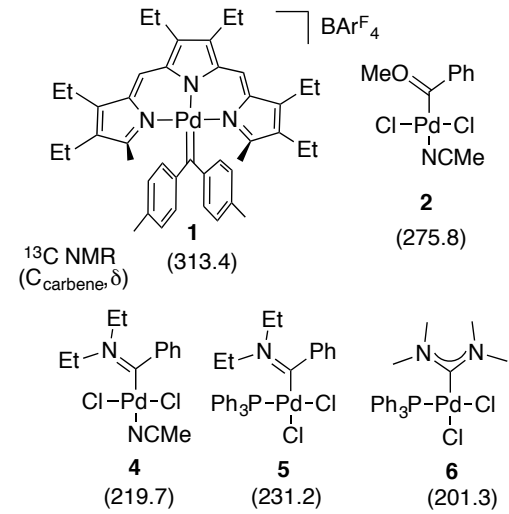

$$
\begin{gathered}
\mathrm{MeO}_{3} \underbrace{\mathrm{P}-\mathrm{Pd}-\mathrm{Cl}}_{3} \\
\mathrm{Cl} \\
\mathbf{3} \\
(281.4)
\end{gathered}
$$

$$
\begin{gathered}
\mathrm{Ph}_{3}{ }^{\mathrm{P}-\mathrm{Pd}-\mathrm{Cl}} \\
\mathrm{Cl} \\
7 \\
(191.4)
\end{gathered}
$$

Figure 2. Palladium(II) carbene complexes with aryl or heteroatom-donor substituents.

The vast majority of palladium(II) carbenes stable enough to be isolated have electron-donating substituents, usually heteroatoms with lone pairs (push-stabilizing substituents). Alkoxo or amino substituents show a good orbital match and the overlap between the carbene empty orbital and the occupied orbital of the $X$ atom effectively reduces the electron deficiency of the carbene carbon (Figure 3 ). The actual electron transfer (O $<\mathrm{N}$ ) reflects the electronegativity of the donor atom and the number of push-substituents is also very important. Therefore, a correlation between the donor ability and number of heteroatoms bound to the $\mathrm{C}_{\text {carbene }}$ on one hand and its electrophilicity on the other is clearly observed (carbene electrophilicity: $\mathrm{OR}>\mathrm{NR}_{2}>2$ $\mathrm{NR}_{2}$ ). The ${ }^{13} \mathrm{C}$ NMR $\mathrm{C}_{\text {carbene }}$ resonances show this trend and the alkoxo carbenes show chemical shifts about 50 ppm higher that the monoamino carbenes (cf. complexes 2-5, Figure 2), ${ }^{[30]}$ and a $30-40 \mathrm{ppm}$ difference is observed between the latter and the

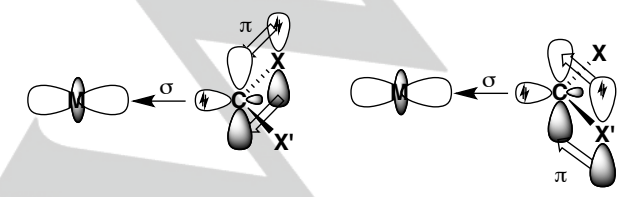

Figure 3. $\pi$-donation to the carbene carbon from $X$ substituents with electron lone pairs. diaminocarbenes $6{ }^{[31]}$ and 7 (Figure 2). ${ }^{[32]}$ This is the general trend for the two other palladium alkoxo carbenes synthesized, ${ }^{[33]}$ and for the more common monoaminocarbenes. ${ }^{[31,34,35]}$ In fact, complex $\mathbf{2}$ is extremely susceptible to nucleophilic attack by water whereas 4 can be handled with no special precautions to exclude water. On the other side, diamino carbenes are quite robust. The vast family of $\mathrm{N}$-heterocyclic carbene (NHC) complexes proves the effectiveness of two nitrogen atoms directly attached to the carbene carbon to stabilize these species. NHCs have become one of the most useful types of auxiliary ligands in palladium catalysis because, in fact, they behave as good donors and because their steric and electronic features can be easily modulated. These complexes and their applications have been thoroughly reviewed and they will not be discussed here any longer. ${ }^{[36]}$ Nonetheless, these derivatives undergo some carbene- $R$ coupling reactions that will be collected in section 4. More recently, some sterically encumbered monoamino carbenes, quite robust as well, have been used as auxiliary ligands in catalysis. ${ }^{[35]}$ The so-called abnormal NHCs (or mesoionic carbenes) are also formal monoamino-carbenes but they are very good donor ligands showing little electrophilicity and high stability that make them suitable for catalytic applications. ${ }^{[37]}$ A few examples of these types of complexes are collected in Figure 4. 
Table 1. Structural parameters for some palladium carbene complexes $\left[\operatorname{Pd}(C R X) Y_{n} L_{3-n}\right]^{m+}(n=1,2 ; m=1,0)$ depicted in Figures $2,4,5$, and 7 .

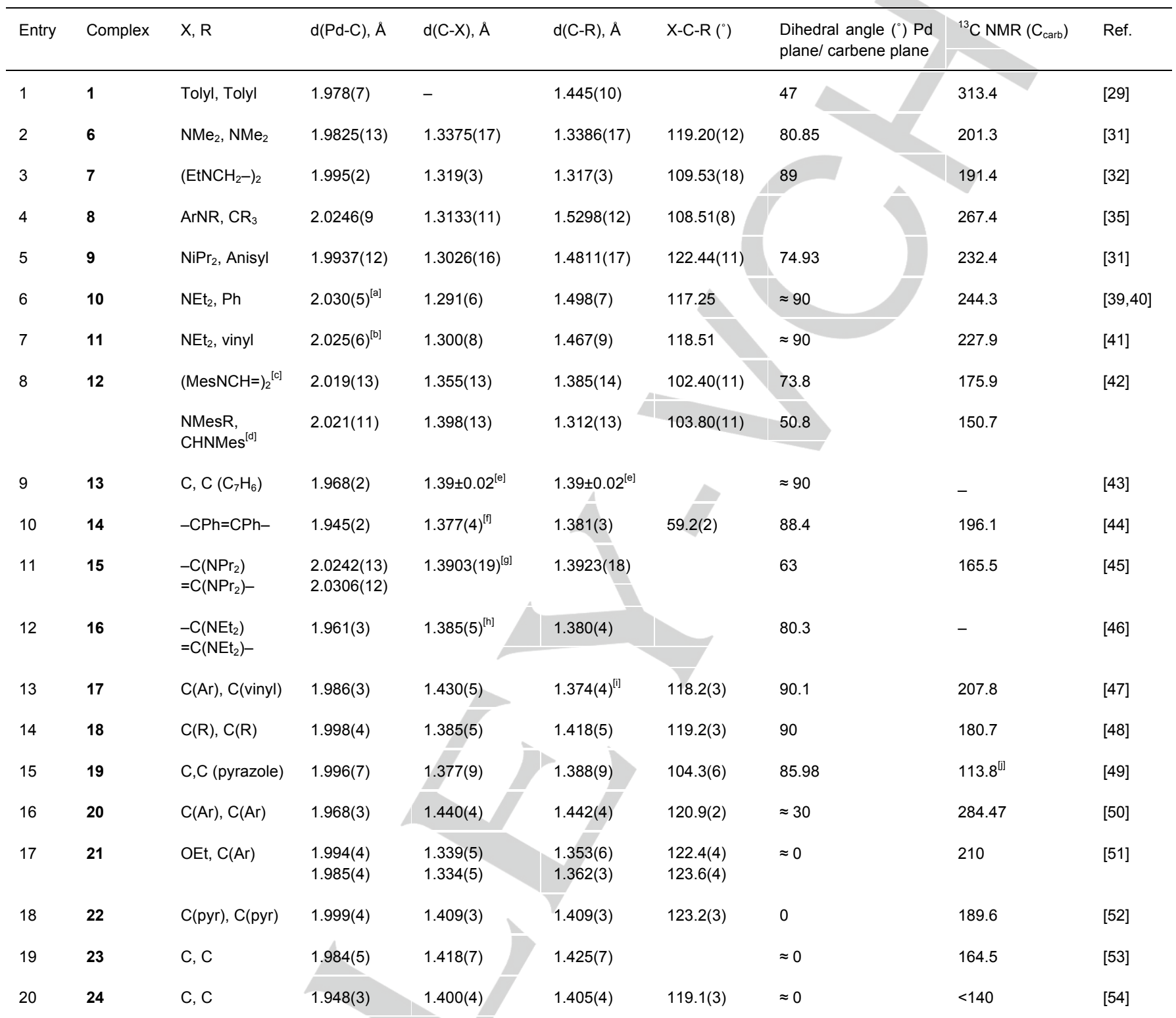

[a] Pd-C $\left(\mathrm{C}_{6} \mathrm{~F}_{5}\right): 2.016(5) \AA$. [b] Pd-C $\left(\mathrm{C}_{6} \mathrm{~F}_{5}\right): 2.031(6)$. [c] $n-\mathrm{NHC}$. [d] a-NHC (MIC). [e] All C-C bond lengths in the cycloheptatrienyl ring are equal (1.39 \pm 0.02$)$. [f] C2-C3: 1.363(3) A. [g] C2-C3 1.3708(19). [h] C2-C3 1.384(5). [i] other bond lenghts ( $\AA$ ): C-C, 1.400(5); C-O, 1.322(4); N-C: 1.349(5). [j] Determined on the more soluble bis(TFA) derivative (instead of bis iodo).

complexes 6-11, Table 1). Thus, the resonant forms depicted in Figures 2 and 4 are the most contributing ones in complexes 211. This is also supported experimentally since complex 3 reacts with chloride and this nucleophile abstracts the methyl group of the methoxy substituent, a typical reaction of oxonium salts, to give a Pd-acyl (Eq. 1). ${ }^{[30]}$

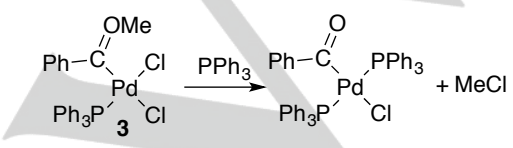

Complex 12 shows two different types of $\mathrm{NHC}$ coordinated to the same metal center. Interestingly, the structural parameters are very similar for the normal $\mathrm{NHC}$ and the mesoinic one (cf. $\mathrm{Pd}-\mathrm{C}$ bond lengths in entry 8 , Table 1). However, the ${ }^{13} \mathrm{C}$ NMR shows a higher field carbene resonance for the mesoionic NHC, and this is an indication that this is more electron-rich than the normal NHC.

The inclusion of the carbene carbon in an aromatic ring reduces the availability of the empty orbital centered on the $\mathrm{C}_{\text {carbene }}$ and therefore its electrophilicity. This is the case of the 
very stable carbocyclic complexes 13-16 (Figure 5 and Table 1) where the $\mathrm{Pd}-\mathrm{C}$ bond is a single one and the carbene ${ }^{13} \mathrm{C}$ NMR resonances (196-165 ppm) are very low compared to complex 1 (313 ppm, Figure 2). ${ }^{[55]}$ The stability of complexes 17-19 (Figure 5) results from a delocalization over the heterocyclic backbone that allows several resonant forms, resulting in a carbene complex of low electrophilicity as shown in Figure 6 for complex 17; structural data (entry 13, Table 1) indicate that resonant form $A$ is the least contributing one. These derivatives are generally called remote $\mathrm{N}$-heterocyclic carbenes. ${ }^{[37 \mathrm{a}]}$

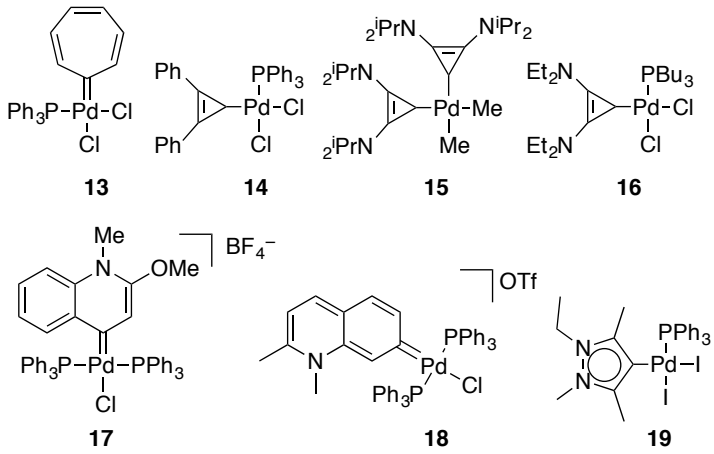

Figure 5. Examples of carbocyclic and remotely stabilized palladium(II) carbenes.

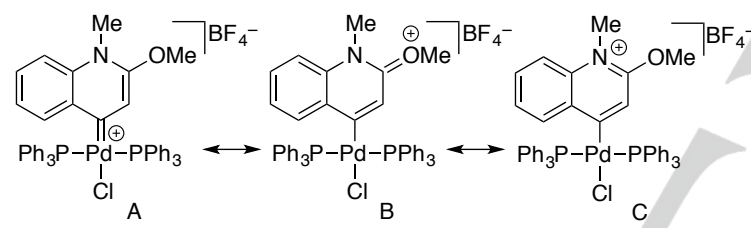

Figure 6. Resonant forms for complex 17 (B and $\mathrm{C}$ are more contributing).

The stability of palladium(II) carbenes can be increased by inclusion of the carbene fragment in a polydentate ligand. Figure 7 collects some examples where the electrophilicity of the carbene carbon vary from complex 20 , which reacts with nucleophiles at the carbene carbon, ${ }^{[50]}$ to 24 , strongly stabilized by delocalization. ${ }^{[54]}$ The ${ }^{13} \mathrm{C}$ NMR chemical shifts for the $\mathrm{C}_{\text {carbene }}$ resonances cover a wide value range, reflecting quite a different

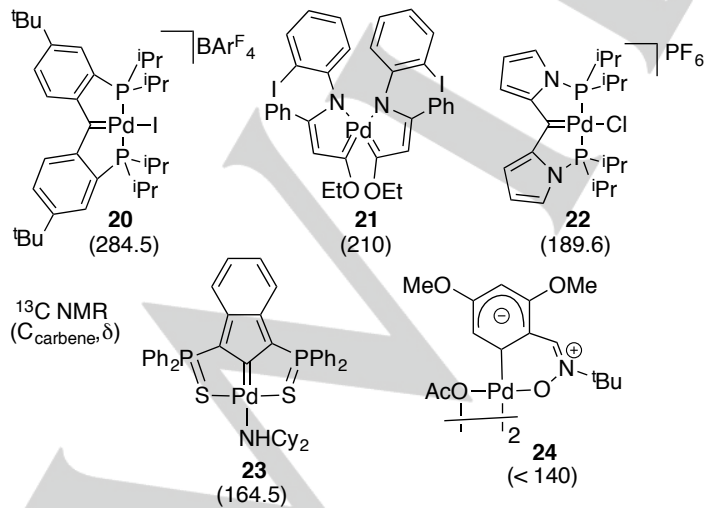

Figure 7. Examples of palladium(II) complexes with a polydentate carbenecontaining ligand. electron density at the carbene center. The carbene in complex $\mathbf{2 1}$ is less electrophilic than its monodentate analogues $\mathbf{2}$ and $\mathbf{3}$, due to the presence of the imido alkenyl substituent that allows an effective electron donation over the entire metalacycle. ${ }^{[51]}$

It is interesting to compare the behavior of complex $\mathbf{2 0}$ with its neutral analogues 25 (Scheme 3). Whereas complex 20 is an electrophilic palladium(II) complex which reacts with a variety of nucleophiles at the carbene carbon, ${ }^{[50]}$ the carbene fragment in complex 25 is actually nucleophilic. ${ }^{[56]}$ Besides undergoing protonation with alcohols, amines or hydrogen chloride, the complex also reacts with weaker acids such as alkynes, ketones, alkylnitriles or polycyclic complexes. In every case the carbene carbon is protonated and the hydrocarbyl group binds to the metal (Scheme 3). ${ }^{[57]}$

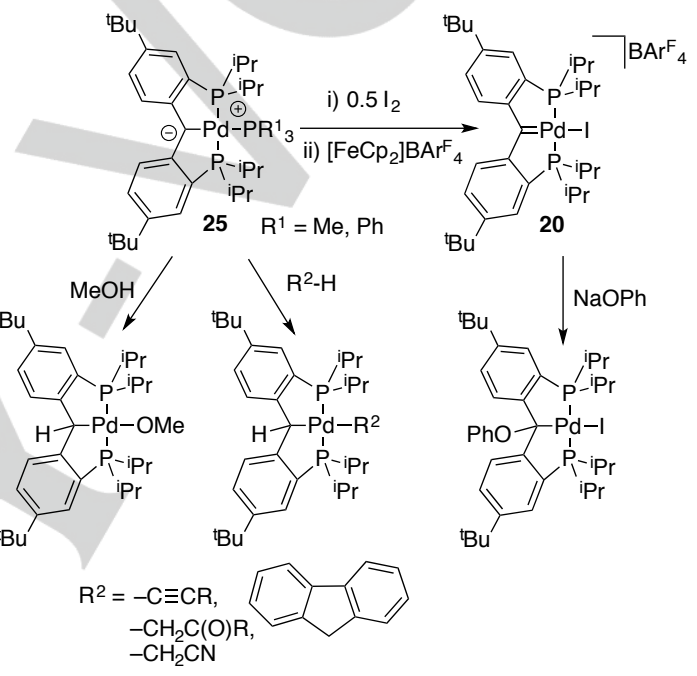

Scheme 3. Divergent reactivity of complexes $\mathbf{2 0}$ and $\mathbf{2 5 .}$

Just looking at the formulation, $\mathbf{2 5}$ could be considered the result of the coordination of a singlet carbene to a $\mathrm{Pd}(0)$ complex. The $\pi$-back donation expected from a $\operatorname{Pd}(0)$ center is larger than that from $\mathrm{Pd}(\mathrm{II})$ and this could increase the electron density of the carbene in such an extent that would make it nucleophilic. However, the molecular structure of $\mathbf{2 5}$ does not show a multiple character for the Pd-C bond and the bond length (2.086(4) $\AA$ for $\mathrm{R}=\mathrm{Me}$ or $2.0755(11) \AA$ for $\mathrm{R}=\mathrm{Ph}$ ) is even longer than that of the cationic 20 (entry 16, Table 1). ${ }^{[56]}$ Thus, 25 is better described as being a $\mathrm{Pd}(\mathrm{II})$ complex containing a bis-anionic methine ligand, an ylide-type ligand with the charge distribution shown in Scheme 3. ${ }^{[50]}$

Complexes 26, ${ }^{[58]}$ and $\mathbf{2 7},{ }^{[59]}$ are other examples of palladium complexes that, having a coordinated disubstituted carbon (formally a carbene), are actually better described as methanediide or bis-ilyde complexes (Scheme 4). They are synthesized from organolithium precursors and the extremely shielded carbon $\left({ }^{13} \mathrm{C}\right.$ NMR Pd-C, -18.3 ppm for complex 27) shows a dramatically different nature than the $\mathrm{Pd}$ (II) carbenes discussed before. The nucleophilic carbon center undergoes reaction with electrophiles as shown in Scheme $4 .^{[58 a]}$ The 
chemistry of this type of complexes has been recently reviewed. ${ }^{[60]}$

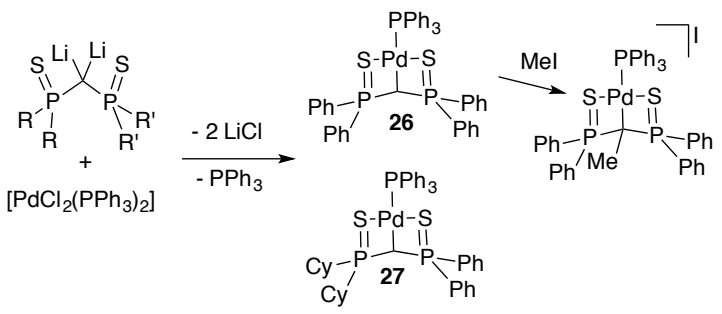

Scheme 4. Some examples of methanediide palladium(II) complexes.

\section{Carbene migratory insertion reactions.}

The study of the carbene migratory insertion reaction in palladium complexes (i.e. B to C, Scheme 5) is often complicated because the relative rates of this reaction and the preceding carbene transfer to palladium (A to $\mathbf{B}$, Scheme 5 ) or the subsequent decomposition of the resulting alkyl complex (C) do not allow the isolation of both relevant intermediate complexes B and C. However, in some cases, these relative rates show a better match, enough for the detection of several of the intermediates depicted in Scheme 5 and to strongly support the migratory insertion pathway.

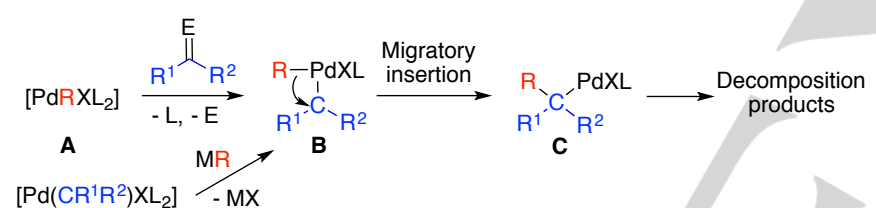

D

Scheme 5. General scheme of the complexes involved in the $\mathrm{C}-\mathrm{C}$ bond formation by migratory insertion in Pd-carbenes.

Most of the reported examples where a migratory insertion reaction has been shown to occur use an isolated palladium hydrocarbyl complex $\mathbf{A}$ and react it with a carbene precursor to isolate the final palladium alkyl $\mathbf{C}$. An early example reported by Van Leeuwen et al. showed that the reaction of a methyl palladium complex with lithiumdichloromethane led to a new complex identified as the chloroethyl palladium derivative 28. By analogy with the platinum complex, the authors propose the formation of a dichloromethyl derivative that rearranges to a palladium carbene. A subsequent migratory insertion into the Pd-Me bond results in the formation of 28 (Scheme 6). ${ }^{[61]}$

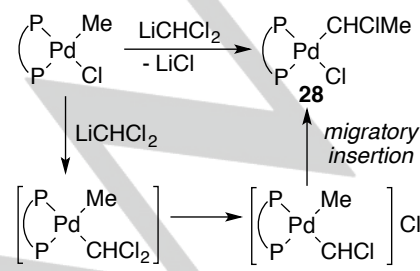

Scheme 6. Insertion of a chloromethylene into a Pd-Me bond.
A related example is the halomethyl $\mathrm{Pd}(\mathrm{IV})$ complex 29 characterized by Cámpora et al. which transforms into $\mathbf{3 0}$ by a formal methylene insertion into the $\mathrm{Pd}$-aryl bond. ${ }^{[62]}$ This process could be interpreted as the formation of a methylene palladium complex followed by the migratory insertion into the Pd-aryl bond (Scheme 7). However, as the authors pointed out, being 29 a $\mathrm{Pd}(\mathrm{IV})$ complex an alternative aryl- $\mathrm{CH}_{2} \mathrm{X}$ reductive elimination followed by oxidative addition of the halobenzyl moiety is plausible and would also lead to $\mathbf{3 0}$.

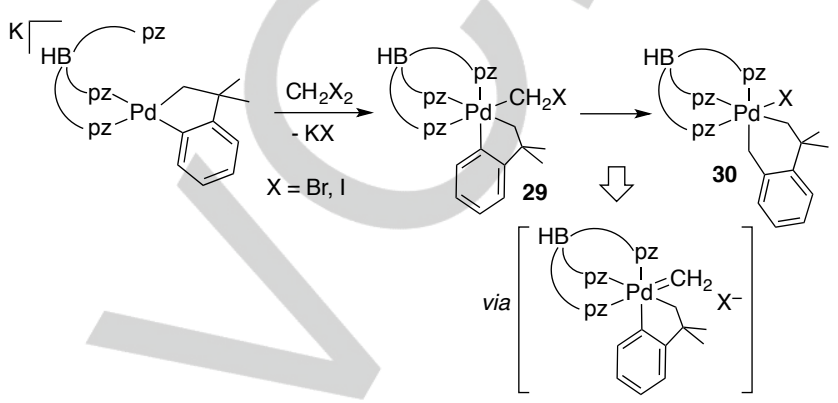

Scheme 7. Formal insertion of a methylene fragment into a Pd(IV)-aryl bond.

Diazoderivatives are one of the most common carbene precursors, also used in catalysis. The reaction of the strained four membered palladacycle in Eq. 2 with the common ethyldiazoacetate (EDA) or trimethylsilyldiazomethane brings about the expansion of the metalacycle with insertion of the $\mathrm{CHR}$ carbene fragment into the Pd-aryl bond to give $31 .{ }^{[63]}$ Again, the intermediate palladium carbene was not detected.

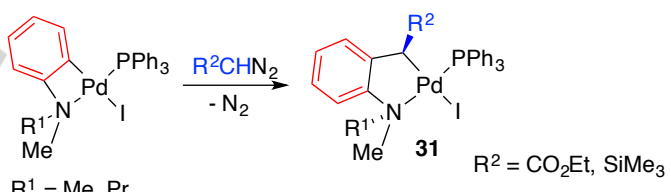

In the course of their catalytic studies W. Y. Yu et al. carried out the reaction of a benzyl palladium complex or a phenyl palladium derivative with diazoalkanes. In contrast with the palladacycles described above, no intermediate carbene or alkyl complexes were detected (B or $\mathbf{C}$ in Scheme 5) and only the organic compounds after decomposition could be characterized (Scheme 8$){ }^{[64]}$ Presumably, the putative palladium alkyl formed after migratory insertion undergoes fast $\beta-\mathrm{H}$ elimination, which is not possible in $\mathbf{3 1}$.

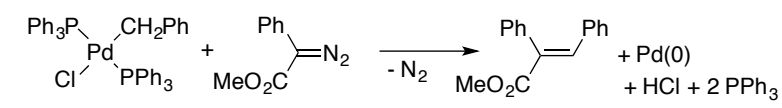

'Bu

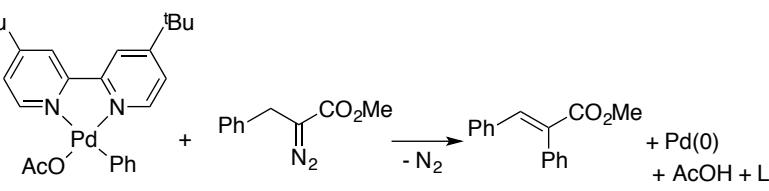

Scheme 8. Reaction of diazoalkanes with Pd-hydrocarbyl complexes. 
A bis-ylide derivative was used by Urriolabeitia et al. as a precursor of a palladium carbene that undergoes a migratory insertion into a $\mathrm{Pd}-\mathrm{C}_{6} \mathrm{~F}_{5}$ bond (Scheme 9, a). The putative pentafluorophenyl palladium carbene-ylide was not detected and only complex 32 , the result of the carbene-aryl coupling, was isolated. However, the intermediacy of the palladium carbeneylide is strongly supported by the isolation of this type of complex from a close related palladium precursor (33, Scheme 9 , b). ${ }^{[65]}$

$$
\text { a) }
$$

b)

$$
{ }_{\mathrm{Pf}^{\prime}}^{\mathrm{Pf} \mathrm{Pd}^{\mathrm{THF}}}+\mathrm{MeO}_{2} \mathrm{THF}_{\mathrm{PPh}_{3}}^{\mathrm{PPh}_{3}} \longrightarrow
$$

Scheme 9. Migratory insertion reaction in carbene-ylide palladium complexes.

Kurosawa et al. reported a rare example of an isolated $\mathrm{Pd}(\mathrm{I})$ dimeric vinylcarbene (34) which forms, upon reaction with tetraphenyltin, a Pd(II) allylic complex 35 (Scheme 10). In this case the starting isolated palladium complex does not bear a Pd-R fragment but a carbene fragment instead (D, Scheme 5). The plausible pathway for the formation of $\mathbf{3 5}$ involves the transmetalation of a $\mathrm{Ph}$ group from tin to palladium followed by migratory insertion reaction and disproportionation of the $\mathrm{Pd}(\mathrm{I})$ complex (Scheme 10). ${ }^{[6]}$

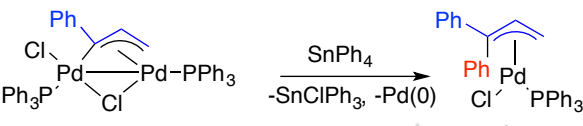

$$
\begin{aligned}
& 34
\end{aligned}
$$

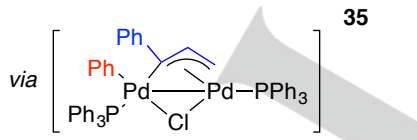

Scheme 10. Evolution of a $\mathrm{Pd}(\mathrm{I})$ vinyl carbene via migratory insertion.

All the examples mentioned so far involve carbene fragments that do not bear donor substituents and therefore they are quite electrophilic and very reactive towards migratory insertion (see below). No intermediate palladium carbene complexes $[\mathrm{PdR}$ (carbene)LX] (B, Scheme 5) could be detected in any of those cases. A way to slow down the migratory insertion reaction would be to use carbene fragments with at least one heteroatom-containing substituent in order to decrease their electrophilicity. We used this strategy in our group, and synthesized palladium carbenes by transmetalation of monoamino or alkoxocarbene fragments from a group 6 metal to palladium. $\left[\mathrm{PdRXL}_{2}\right]\left(\mathrm{R}=\mathrm{C}_{6} \mathrm{~F}_{5}, \mathrm{Me}\right.$, acyl) complexes $(\mathbf{A}$, Scheme
5) were used as palladium precursors, and mainly $\left[\mathrm{W}(\mathrm{CO})_{5}\right.$ (carbene)] derivatives as the carbene source, although the carbene transmetalation also occurs for the analogous chromium complexes. As a whole, the results obtained for the reactions with different $R$ groups in $\left[\mathrm{PdRXL}_{2}\right]$ and different carbene fragments draw a complete picture of the migratory insertion on palladium carbenes, with the detection of all the intermediates in Scheme 5.

The reactions of methoxy carbene tungsten complexes with $\left[\mathrm{Pd}\left(\mathrm{C}_{6} \mathrm{~F}_{5}\right) \mathrm{Br}(\mathrm{NCMe})_{2}\right]$ do not allow to detect the intermediate pentafluorophenyl carbene palladium complex but only the products of the migratory insertion reaction (Scheme 11). ${ }^{[4]}$ The transmetalation of this carbene fragment from $\mathrm{W}$ to $\mathrm{Pd}$ does occur, as we have observed in the formation of complex 2 (Eq. 3). ${ }^{[30]}$

$$
(\mathrm{OC})_{5} \mathrm{~W}=\mathrm{C}_{\mathrm{Ph}}^{\mathrm{OMMe}}+\left[\mathrm{PdCl}_{2}(\mathrm{NCMe})_{2}\right] \underset{\mathrm{NCMe}}{\left[\mathrm{W}(\mathrm{CO})_{5}(\mathrm{NCMe})\right]} \stackrel{\mathrm{Ph}_{\mathrm{Cl}^{\prime}} \mathrm{Cl}_{2}^{\prime \prime} \mathrm{Pd}^{\prime \prime} \mathrm{Cl}}{\mathrm{OMCMe}}
$$

Thus, the putative palladium methoxycarbenes in Scheme 11 must undergo a fast migratory insertion reaction even when the hydrocarbyl group on palladium is pentafluorophenyl, a fragment that forms a strong $\mathrm{Pd}-\mathrm{C}$ bond and it is known to undergo slower insertion reactions that a phenyl group. ${ }^{[67]}$ With a right choice of substituent $R^{1}$ on the carbene fragment, the resulting palladium alkyls (C, Scheme 5) can be trapped by formation of a palladium allyl $(36),{ }^{[40,68]}$ or a palladium benzylic complex $(37) \cdot{ }^{[39,40]}$ For $\mathrm{R}^{1}$ $=\mathrm{Me}$ a fast $\beta-\mathrm{H}$ elimination leads to the arylated vinyl ether (Scheme 11).

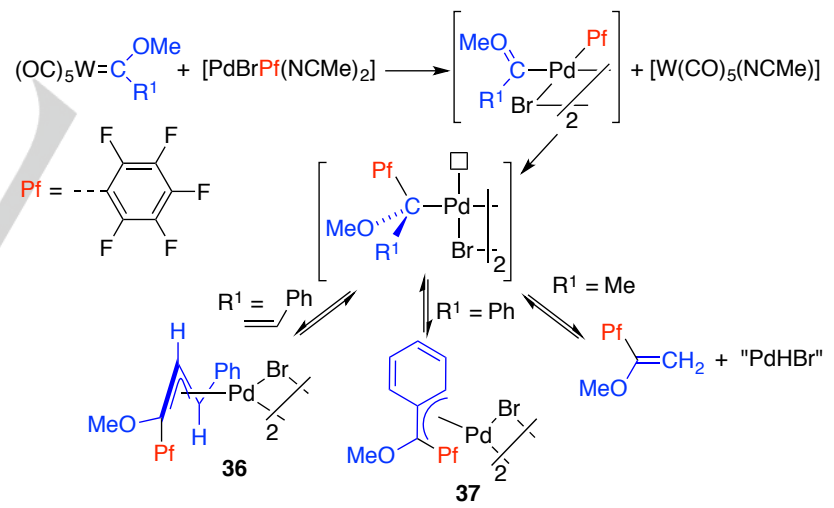

Scheme 11. Products of the migratory insertion of a methoxycarbene into the $\mathrm{Pd}-\mathrm{C}_{6} \mathrm{~F}_{5}$ bond.

The reaction of the monoamino carbene tungsten complex with the pentafluorophenyl palladium precursor led to the formation of a dimeric palladium carbene (38) that can be isolated and used as starting material for the synthesis of other $\left[\mathrm{Pd}\left(\mathrm{C}_{6} \mathrm{~F}_{5}\right)\right.$ (carbene)LX] derivatives (Scheme 12). ${ }^{[39-41]}$ In contrast to the methoxy carbene, the better electron-donor amino group reduces the electrophilicity of the palladium carbene fragment and increases the stability of the complexes. A slow migratory insertion reaction follows to give a palladium alkyl complex that could not be detected in this case (see below for other detected examples). When $\mathrm{R}^{1}=\mathrm{Me}$, the evolution of this alkyl by $\beta-\mathrm{H}$ 
elimination leads to the substituted vinyl amine (analogous to the vinylic ether in Scheme 11). In these reactions the aryl-carbene coupling also leads to the formation of iminium salts, the product of a formal reductive elimination, that could be generated from the putative aminoalkyl palladium complex after migratory insertion or even directly form $38 .{ }^{[40]}$

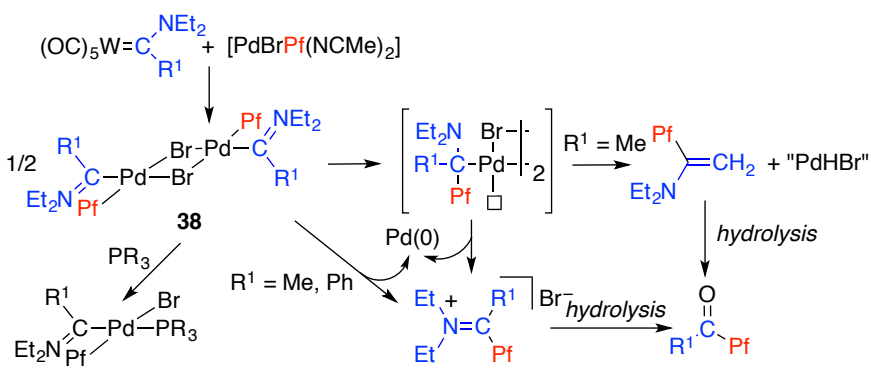

Scheme 12. Carbene-pentafuorophenyl coupling in a monoaminocarbene palladium complex.

Scheme 13 shows a comparison of the reactivity of the monoamino and alkoxo carbene fragments where $R^{1}=2$-phenyl ethenyl. As mentioned before, the more stable palladium monoamino carbenes $(\mathbf{3 8}, \mathbf{1 1})$ can be isolated and undergo a slow carbene- $\mathrm{C}_{6} \mathrm{~F}_{5}$ coupling whereas a fast migratory insertion reaction occurs for the analogous alkoxo carbenes leading to a palladium alkyl stabilized in the $\eta^{3}$-allylic form, 36. A free iminium salt results from the decomposition of the dimeric complex 38 . However, the evolution of $\mathbf{1 1}$ leads to a coupled organic fragment that remains coordinated to palladium (39).

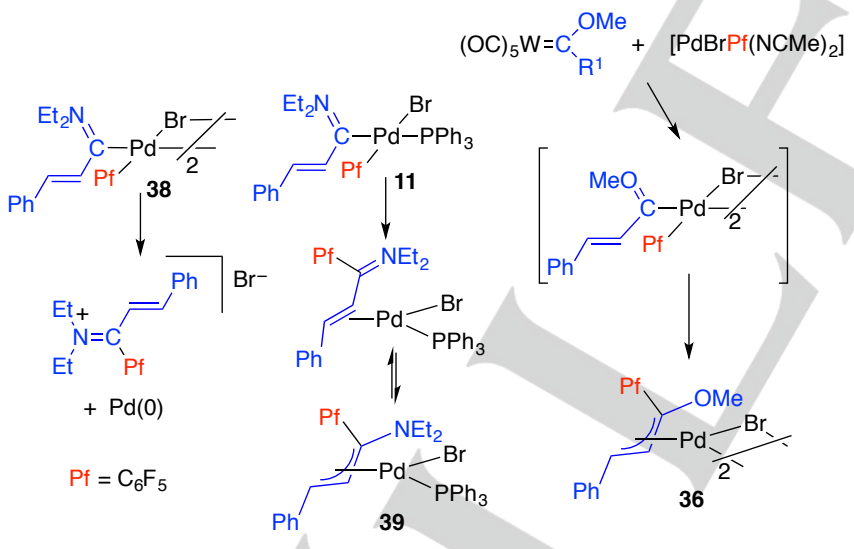

Scheme 13. Carbene-pentafuorophenyl coupling products in heteroatomsubstituted vinylic carbene palladium species.

Interestingly, complex $\mathbf{3 9}$ in the solid state can be described as a zwitterionic $\mathrm{Pd}(0)$ complex with a coordinated iminium ligand. However, the spectroscopic data in solution point to a predominant $\mathrm{Pd}(\mathrm{II}) \eta^{3}$-allylic form analogous to $36 .{ }^{[41]}$ The occurrence of this intermediate situation supports a common carbene- $\mathrm{R}$ coupling route through migratory insertion for both the monoamino and alkoxo carbenes.
Both complexes involved in the migratory insertion sequence (B to $\mathbf{C}$, Scheme 5) were characterized in the reaction shown in Scheme 14. Complex $\mathbf{4 0}$ evolves by migratory insertion of the monoaminocarbene into Pd-acyl bond and the alkyl derivative $\mathbf{4 1}$ was detected and characterized in solution. ${ }^{[69]}$ Besides a facile protonation of the enolate group, this complex also undergoes a decomposition reaction to the iminium salt.

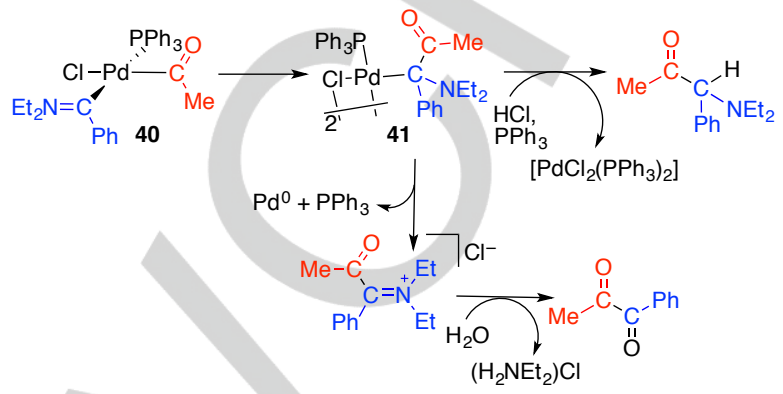

Scheme 14. Migratory insertion reaction of a monoaminocarbene into a $\mathrm{Pd}$ acyl bond.

The monitorization of the decomposition of complexes $\left[\mathrm{PdR}\left\{\mathrm{C}\left(\mathrm{NEt}_{2}\right) \mathrm{Ph}\right\} \mathrm{X}\left(\mathrm{PPh}_{3}\right)\right] \quad\left(\mathrm{R}=\mathrm{C}(\mathrm{O}) \mathrm{Me}, \mathrm{C}_{6} \mathrm{~F}_{5} ; \mathrm{X}=\mathrm{Cl}, \mathrm{Br}\right.$; Schemes 12 and 14$)$ showed that the migratory insertion is first order in palladium and independent of the concentration of phosphine. ${ }^{[69]}$ This indicates that in these cis-carbene- $R$ complexes the reaction is intramolecular and does not need of previous ligand dissociation to occur. The highest influence in the migratory insertion rate is exerted by the carbene fragment: large differences are observed in the reactivity of diamino and monoamino or alkoxo carbenes, as it is shown in Scheme 15. ${ }^{[40]}$ In the series of complexes $\left[\operatorname{PdBr}\left(\mathrm{C}_{6} \mathrm{~F}_{5}\right)\left\{\mathrm{C}\left(\mathrm{NEt}_{2}\right) \mathrm{Ph}\right\} \mathrm{L}\right]$ the better $\sigma$-donating the ligand $L$, the slower the reaction, although the differences are far smaller than those observed for the carbene fragments. The following trend in rate was found: $\mu-\mathrm{Br}$ (dimer 38) $\approx \mathrm{PPh}_{3}>\mathrm{PCy}_{3}, \mathrm{PMe}_{3}>\mathrm{NHEt}_{2}$. The cationic $\left[\mathrm{Pd}\left(\mathrm{C}_{6} \mathrm{~F}_{5}\right)\left\{\mathrm{C}\left(\mathrm{NEt}_{2}\right) \mathrm{Ph}\right\}(\mathrm{NCMe})_{2}\right]^{+}$showed the higher rate, indicating that a more electrophilic metal center is favoring the insertion reaction. ${ }^{[70]}$

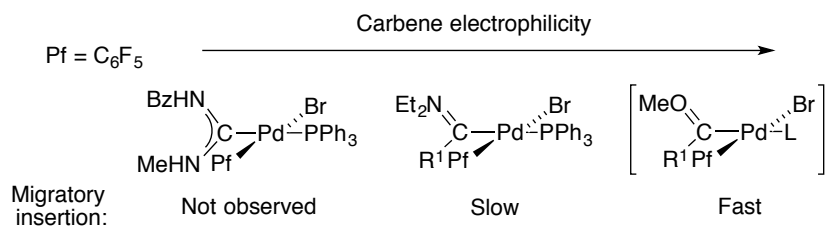

Scheme 15 . Relative reactivity of heteroatom-substituted palladium carbenes.

The migratory insertion reaction is not restricted to a specific $\mathrm{Pd}-\mathrm{R}$ group in $[\mathrm{PdR}$ (carbene $\mathrm{XL}]$ complexes. As it has been discussed above, aryl and acyl groups experience the process, but the reaction also takes place for $R=M e .{ }^{[69]}$ 
Scheme 16 summarizes the reaction pathways followed by a mixture of $\left[\mathrm{W}(\mathrm{CO})_{5}\{\mathrm{C}(\mathrm{OMe}) \mathrm{Ph}\}\right]$ and a methyl palladium precursor.

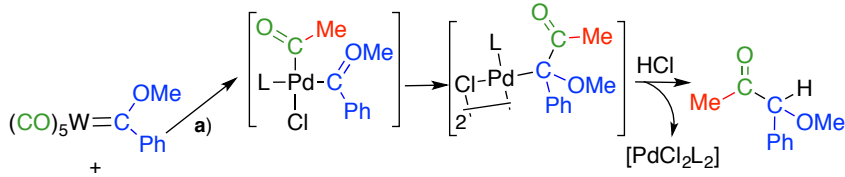

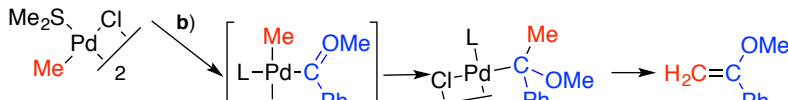

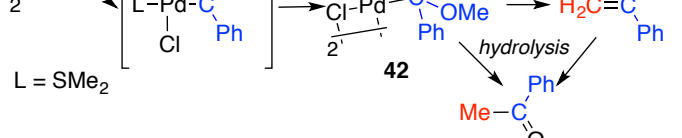

Scheme 16. Migratory insertion reaction of an alkoxocarbene into a Pd-Me bond (b).

Pathway a (Scheme 16) shows the migratory insertion reaction of a Pd-acyl group formed in the reaction mixture, a route which is analogous to that shown in Scheme 14 for a monoamino carbene. When group 6-metal pentacarbonyl carbene complexes are used as carbene sources, both the carbene and a carbonyl ligand are actually transferred to palladium. This may be irrelevant provided the carbonyl acts just as a ligand since, being weakly coordinated to $\mathrm{Pd}(\mathrm{II})$, it is easily displaced and, in fact, its coordination has never been observed in these systems. However, in the presence of a $\mathrm{Pd}-\mathrm{R}$ bond, CO migratory insertion occurs to give the $\mathrm{Pd}-\mathrm{C}(\mathrm{O}) \mathrm{R}$ acyl complexes. This process takes place for $\mathrm{R}=\mathrm{Me}, \mathrm{Ph}$ but not for $\mathrm{R}=\mathrm{C}_{6} \mathrm{~F}_{5}$, a group that disfavors the formation of the acyl group. The carbonyl transfer is faster than the carbene transfer for monoaminocarbenes, and for $\mathrm{R}=\mathrm{Me}, \mathrm{Ph}$ only the acyl palladium carbene is observed (Eq. 4). ${ }^{[71]}$ However the rate of carbene transfer vs acyl formation is closer for the methoxy carbene and the product of migratory insertion of the carbene into the Pd-Me bond (42, path b, Scheme 16) could be observed and characterized. ${ }^{[69]}$

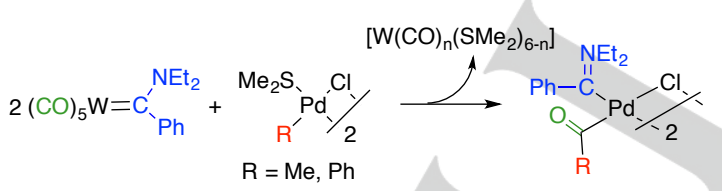

Danopoulos, Green et al. described the unusual formation of the product of a migratory insertion of an N-heterocycic carbene (NHC) into a Pd-Me bond (Scheme 17). ${ }^{[72]}$ Complex 43 was obtained by reaction of a dimethyl palladium complex and the free chelating carbene ligand. DFT calculations on the system support the formation of a pentacoordinated palladium complex $\left[\mathrm{PdLMe}_{2}\right]$ followed by the migration of a methyl group to one of the $\mathrm{Pd}-\mathrm{C}$ (carbene) fragments. The barrier for this process was found to be low $\left(7.8 \mathrm{kcal} \mathrm{mol}^{-1}\right)$. This is an unusual outcome for NHC palladium complexes where, if the hydrocarbyl-carbene coupling takes place, it generally leads to the corresponding azolium salt and $\operatorname{Pd}(0)$ (see section 4 ). The presence of a rigid chelating carbene in this example may force the reaction to occur in the high energy pentacoordinated intermediate as well as favor the stabilization of complex 43. In any case, it clearly shows that a migratory insertion reaction is also possible for NHC-palladium carbenes.

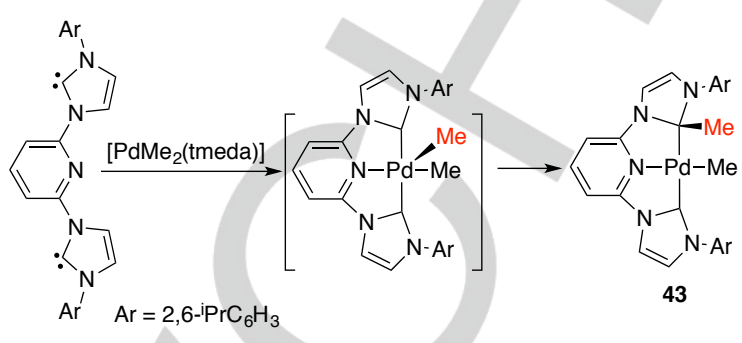

Scheme 17. Migratory insertion reaction of a NHC into a Pd-Me bond.

The experimental studies collected here show that migratory insertion is quite general, being observed for a variety of Pdhydrocarbyl groups as well as carbene fragments with different electronic features. A wide range of reaction rates are observed, which shows a correlation with the electrophilic nature of the carbene, this being the main factor in determining the ease of the reaction. As a consequence, the isolation of relevant intermediates for the most electrophilic carbene fragments, often used in catalysis, is difficult and DFT calculations have been carried out on some of these systems in order to find out the feasibility of the migratory insertion step in a catalytic cycle. The barriers found for the migratory insertion step (B to $\mathbf{C}$, Scheme 5) are generally low for electrophilic carbene fragments such as $\mathrm{Pd}-\mathrm{CRR}$, or $\mathrm{Pd}-\mathrm{C}(\mathrm{OR}) \mathrm{R}^{\prime}$ with values in the range $3.6-7.6 \mathrm{kcal}$ $\mathrm{mol}^{-1}[18 \mathrm{c}, 73]$ Therefore, when precursors of these carbene fragments are used in catalytic reactions of the type shown in Scheme 2, the migratory insertion reaction is not expected to be rate limiting.

\section{Carbene-Hydrocarbyl coupling reactions of NHCs.}

$\mathrm{N}$-heterocyclic carbenes (NHCs) are extremely useful as auxiliary ligands in a wide variety of palladium catalyzed reactions. As mentioned above, their coordination chemistry and applications have been periodically and thoroughly reviewed. ${ }^{[36]}$ These ligands are very attractive for the stability they impart to the metal complexes and because of the possibility to modulate both their electronic and steric features. However the Pd-NHC linkage is not utterly inert. In 1998 Cavell et al. reported the decomposition of a palladium complex by the coupling of an imidazolium-based NHC and a methyl group (Eq. 5). ${ }^{[74]}$

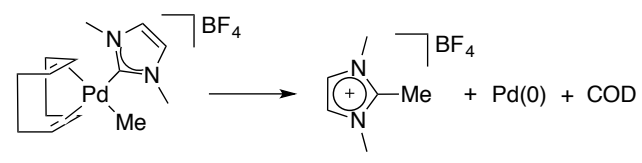


This is a process where the NHC ceases to play a spectator ligand role and, since complexes of a general formulation $[\mathrm{PdR}(\mathrm{NHC}) L X]$ are ubiquitous in $\mathrm{Pd}$-catalysis, this is a potential catalyst decomposition pathway. The reaction produces an imidazolium salt and $\mathrm{Pd}(0)$ and it is formally a reductive elimination process. Subsequent studies by the same group and DFT calculations support that this is indeed the reaction pathway. The calculated transition state for the coupling is a three-center $\mathrm{R}-\mathrm{Pd}-\mathrm{C}(\mathrm{NHC}) \mathrm{TS}$ that leads to an encounter complex with little interaction between the metal and the imidazolium $\mathrm{C}$-2 carbon. ${ }^{[75]}$ The NHC-R reductive elimination is not rare and has been reported for imidazolium salts and a variety of $\mathrm{R}$ groups including methyl, ${ }^{[74-77]}$ acyl, ${ }^{[78]}$ allyl, ${ }^{[79]}$ and aryl (Eq. 6). ${ }^{[80,81]}$ Several reviews on the subject are available. ${ }^{[82,83]}$

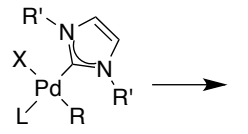

$$
\underset{\substack{L_{R^{\prime}} \\ \mathrm{R}^{\prime}}}{\mathrm{R}^{\prime}}-\mathrm{R}+\operatorname{Pd}(0)+L
$$

$\mathrm{R}=\mathrm{Me}$, acyl, allyl, aryl

Eq. 7 shows an example of the reductive elimination of a phenylsubstituted imidazolium salt from a well-defined aryl palladium $\mathrm{NHC}$ complex reported by Marshall and Grushin. ${ }^{[80]}$ A kinetic study of the decomposition of $\mathbf{4 4}$ shows that the reaction occurs by initial phosphine dissociation. However, this is not a general case since no effect of the phosphine concentration in the reaction rate was observed for other close related systems.

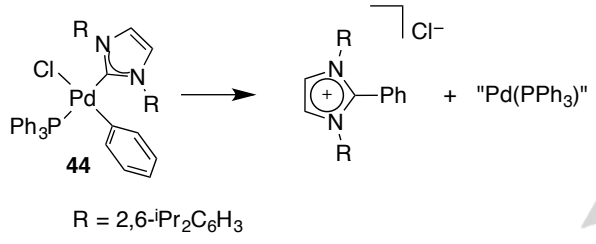

The decomposition of NHC-palladium hydrocarbyl complexes by reductive elimination is more difficult if the attainment of the required three-center transition state is disfavored by steric constraints. This is observed in the case of complexes with chelating $\mathrm{NHC}$ carbenes, the more rigid the structure the more stable the $\mathrm{NHC}$ complexes. ${ }^{[76]}$ Also, chelating auxiliary ligands in $\left[\mathrm{PdR}(\mathrm{NHC}) \mathrm{L}_{2}\right]^{+}\left(\mathrm{L}_{2}=\right.$ chelating phosphine, $\left.\mathrm{L}=\mathrm{PR}_{3}\right)$ increase the stability of the complexes, since the opening of the L-Pd-L angle that occurs in the transition state (concomitant to the decrease in the R-Pd-C(carbene) angle) is not as favorable as in the case of two monodentate $L$ ligands. ${ }^{\text {[75] }}$

In these processes, the Pd-NHC moiety behaves in the same way as a Pd- $\sigma$-bonded hydrocarbyl fragment. With the exception of the example shown in Scheme 17, a reductive elimination pathway, with the concomitant formation of the free azolium salt, is the observed carbene-hydrocarbyl coupling mechanism. The reverse reaction, the oxidative addition of imidazolium salts to $\mathrm{Pd}(0)$ has been described, ${ }^{\left[{ }^{84}\right]}$ including the reaction of a bisimidazolium salt to $\left[\mathrm{Pd}\left(\mathrm{PPh}_{3}\right)_{4}\right]$ which involves the cleavage of a $\mathrm{C}-\mathrm{C}$ bond and the formation of a bis-NHC-Pd(II) carbene complex. ${ }^{[85]}$

\section{Conclusions.}

The role played by reactive palladium carbenes in catalysis is gaining importance. The carbene fragment can be introduced in the final products through the formation of two new $\mathrm{C}-\mathrm{C}$ bonds and this builds up molecular complexity in a lower number of reaction steps. The carbene migratory insertion reaction is the key process that allows to form a first C-C(carbene) bond and leads to a palladium alkyl that can be further functionalized (by a C-C coupling reaction or other transformations) to the final polyfunctionalized product. The many proposals of catalytic cycles that include a carbene migratory insertion step are supported by examples of this process in stoichiometric reactions of well-defined palladium precursors as described above. The rate of the migratory insertion is mainly determined by the electrophilicity of the carbene carbon bound to palladium and wide variations can be found between the fastest very electrophilic PdCRR' carbenes ( $R, R^{\prime}=$ hydrocarbyls not included in an aromatic ring), where reaction intermediates are elusive, and the electron richer diamino-substituted, or the $\mathrm{N}$ heterocyclic carbenes, with very low reactivity. Using heteroatom monosubstituted palladium carbenes of intermediate electrophilicity, and therefore intermediate migratory insertion rates, all the intermediates involved in a $\mathrm{C}-\mathrm{C}$ formation through carbene migratory insertion can be characterized, providing a solid ground for the whole description of this process. When extending the Pd-catalyzed couplings involving carbene precursors to different types of carbene fragments, it should be born in mind that the nature of the palladium carbene may render the migratory insertion step either unimportant to determine the turnover rate in the fastest cases, or strongly controlling the overall reaction rate for less electrophilic Pdcarbenes.

Pd-carbene chemistry shows a completely different face in catalysis when carbenes are used as auxiliary ligands, taking advantage of the robustness of the $\mathrm{N}$-heterocyclic carbenes or related electron rich carbenes. However, a carbene-hydrocarbyl reductive elimination on the metal appears in this context as one of the few catalyst decomposition pathways described for these complexes. Rarely used as a product-forming step in catalytic reactions, that would produce substituted azolium salts, this reaction is of great importance in evaluating the stability of the palladium complexes with these ligands in the course of the catalytic reaction.

\section{Acknowledgements}

Financial support from the Spanish MINECO (SGPI, grant CTQ2016-80913-P) is gratefully acknowledged. I would like also to thank Alberto Pérez-Mateo and Isabel Meana for their help with some graphic material and Pablo Espinet for useful discussions.

Keywords: carbenes $\cdot$ palladium $\cdot$ migratory insertion $\cdot \mathrm{C}-\mathrm{C}$ coupling $\cdot$ transmetalation 
[1] N. Miyaura, A. Suzuki, Chem. Rev. 1995, 95, 2457-2483.

[2] J. K. Stille, Angew. Chem. Int. Ed. Engl. 1986, 25, 508-524.

[3] E.-I. Negishi, Acc. Chem. Res. 1982, 15, 340-348.

[4] a) T. Hiyama, E. Shirakawa, Top. Curr. Chem. 2002, 219, 61- 85; b) T. Hiyama, J. Organomet. Chem. 2002, 653, 58-61.

[5] M. Kumada, Pure Appl. Chem. 1980, 52, 669-679.

[6] a) Louie, J.; Hartwig, J. F. Tetrahedron Lett. 1995, 36, 3609-3612; b) Guram, A. S.; Rennels, R. A.; Buchwald, S. L. Angew. Chem., Int. Ed. Engl. 1995, 34, 1348-1350.

[7] K. Sonogashira in Comprehensive Organic Synthesis (Eds.: B. M. Trost, I. Fleming), Pergamon Press, Oxford, 1991, vol. 3, pp. 521-549.

[8] R. F. Heck, Org. React. 1982, 27, 345-390.

[9] a) M. Palucki, S. L. Buchwald, J. Am. Chem. Soc. 1997, 119, 1110811109; b) B. C. Hamann, J. F. Hartwig, J. Am. Chem. Soc. 1997, 119 12382-12383.

[10] a) L. Ackermann, Chem. Rev. 2011, 111, 1315-1345; b) N. Kuhl, M. N. Hopkinson, J. Wencel-Delord, F. Glorius, Angew. Chem. Int. Ed. 2012 51, 10236-10254; c) J. He, M. Wasa, K. S. L. Chan, Q. Shao, J. -Q. Yu, Chem. Rev. 2017, 117, 8754-8786; d) Y. Yang, J. Lan, J. You, Chem. Rev. 2017, 117, 8787-8863.

[11] a) K. L. Greenman, D. S. Carter, D. L. Van Vranken, Tetrahedron 2001, 57, 5219-5225; b) K. L. Greenman, D. L. Van Vranken, Tetrahedron 2005, 61, 6438-6441.

[12] J. Barluenga, P. Moriel, C. Valdés, F. Aznar. Angew. Chem. Int. Ed. 2007, 46, 5587-5590

[13] a) J. Barluenga, M. Tomás-Gamasa, P. Moriel, F. Aznar, C. Valdés, Chem. Eur. J. 2008, 14, 4792-4795; b) J. Barluenga, M. Escribano, P. Moriel, F. Aznar, C. Valdés, Chem. Eur. J. 2009, 15, 13291-13294; c) J. Barluenga, M. Escribano, F. Aznar, C. Valdés, Angew. Chem. Int. Ed. 2010, 49, 6856-6859; d) L. Florentino, F. Aznar, C. Valdés, Chem. Eur. J. 2013, 19, 10506-10510; e) A. Jiménez-Aquino, J. A. Vega, A. A Trabanco, C. Valdés, Adv. Synth. Catal. 2014, 356, 1079-1084; f) M. Paraja, C. Valdés, Chem. Commun. 2016, 52, 6312-6315; g) R. Barroso, M. Paraja, M. P. Cabal, C. Valdés, Org. Lett. 2017, 19, 40864089.

[14] a) C. Peng, Y. Wang, J. Wang, J. Am. Chem. Soc. 2008, 130, 15661567; b) S. Chen, J. Wang, Chem. Commun. 2008, 4198-4200; c) Q. Xiao, J. Ma, Y. Yang, Y. Zhang, J. Wang, Org. Lett. 2009, 11, 4732 4735; d) Z. Zhang, Y. Liu, M. Gong, X. Zhao, Y. Zhang, J. Wang Angew. Chem. Int. Ed. 2010, 49, 1139-1142; e) L. Zhou, F. Ye, Y. Zhang, J. Wang, J. Am. Chem. Soc. 2010, 132, 13590-13591; f) L. Zhou, F. Ye, J. Ma, Y. Zhang, J. Wang, Angew. Chem. Int. Ed. 2011 50, 3510-3514; g) Q. Xiao, B. Wang, L. Tian, Y. Yang, J. Ma, Y. Zhang, S. Chen, J. Wang, Angew. Chem. Int. Ed. 2013, 52, 9305-9308; h) Y Xia, F. Hu, Z. Liu, P. Qu, R. Ge, C. Ma, Y. Zhang, J. Wang, Org. Lett. 2013, 15, 1784-1787; i) X. Wang, Y. Xu, Y. Deng, Y. Zhou, J. Feng, G. Ji, Y. Zhang, J. Wang, Chem. Eur. J. 2014, 20, 961-965; j) S. Xu, R. Chen, Z. Fu, Q. Zhou, Y. Zhang, J. Wang, ACS Catal. 2017, 7, 19931997.

[15] a) R. Kudirka, S. K. J. Devine, C. S. Adams, D. L. Van Vranken, Angew. Chem. Int. Ed. 2009, 48, 3677-3680; b) A. Khanna, C. Maung K. R. Johnson, T. T. Luong, D. L. Van Vranken, Org. Lett. 2012, 14 3233-3235; c) E. S. Gutman, V. Arredondo, D. L. Van Vranken, Org Lett. 2014, 16, 5498-5501.

[16] a) Z. -S. Chen, X. -H. Duan, P. -X. Zhou, S. Ali, J. -Y. Luo, Y. -M Liang, Angew. Chem. Int. Ed. 2012, 51, 1370-1374; b) H. Chen, L. Huang, W. Fu, X. Liu, H. Jiang, Chem. Eur. J. 2012, 18, 10497-10500; c) X. Gao, B. Wu, W. -X. Huang, M. -W. Chen, Y. -G. Zhou, Angew. Chem. Int. Ed. 2015, 54, 11956 -1960; d) Q. Dai, Y. Jiang, S. Guo, J. T. Yu, J. Cheng, Chem.Commun. 2015, 51, 14781-14784; e) G. Qin, L. Li, J. Li, H. Huang, J. Am. Chem. Soc. 2015, 137, 12490-12493; f) X. S. Shang, N. T. Li, H. X. Siyang, P. N. Liu, J. Org. Chem. 2015, 80, 48084815; g) J. Feng, B. Li, Y. He, Z. Gu, Angew. Chem. Int. Ed. 2016, 55
2186-2190; h) D. Arunprasath, B. D. Bala, G. Sekar, Org. Lett. 2017 $19,5280-5283$.

[17] M. Jia, S. Ma, Angew. Chem. Int. Ed. 2016, 55, 9134-9166.

[18] a) M. Gómez-Gallego, M. J. Mancheño, M. A. Sierra. Acc. Chem. Res. 2005, 38, 44-53; b) K. Wang, Y. Ping, T. Chang, J. Wang, Angew. Chem. Int. Ed. 2017, 56, 13140-13144; c) K. Wang, Y. Lu, F. Hu, J. Yang, Y. Zhang, Z. -X. Wang, J. Wang, Organometallics 2018, 37, $1-10$.

[19] W. R. Bamford, T. S. Stevens, J. Chem. Soc. 1952, 4735-4740.

[20] J. Barluenga, C. Valdés. Angew. Chem. Int. Ed. 2011, 50, 7486-7500.

[21] a) Y. Zhang, J. Wang. Eur. J. Org. Chem. 2011, 1015-1026; b) Z. Shao, H. Zhang, Chem. Soc. Rev., 2012, 41, 560-572; c) Z. Liu, J. Wang, J. Org. Chem. 2013, 78, 10024-10030; d) Q. Xiao, Y. Zhang, J. Wang. Acc. Chem. Res. 2013, 46, 236-247; e) Y. Xia, Y. Zhang, J. Wang. ACS Catal. 2013, 3, 2586-2598

[22] a) Y. Xia, D. Qiu, J. Wang. Chem. Rev. 2017, 117, 13810-13889; b) R. Barroso, M. P. Cabal, C. Valdés. Synthesis 2017, 49, 4434-4447; c) M. Peña-López, M. Beller. Angew. Chem. Int. Ed. 2017, 56, 46-48; d) Y. Xia, J. Wang. Chem. Soc. Rev., 2017, 46, 2306-2362.

[23] a) M. J. Calhorda, J. M. Brown, N. A. Cooley, Organometallics 1991, 10 , 1431-1438; b) G. Mann, D. Baranano, J. F. Hartwig, A. L. Rheingold, I. A. Guzei J. Am. Chem. Soc. 1998, 120, 9205-9219; c) D. S McGuinness, B. F. Yates, K. J. Cavell, Organometallics 2002, 21, 54085414

[24] a) R. K. Armstrong, J. Org. Chem. 1966, 31, 618-620; b) R. A. Paulissen, A. J. Hubert, P. Teyssie, Tetrahedron Lett. 1972, 13, 1465-1466 c) F. Bernardi, A. Bottoni, G. P. Miscione, Organometallics 2001, 20, 2751-2758; d) C. Rodríguez-García, A. Oliva, R. M. Ortuño, V. Branchadell, J. Am. Chem. Soc. 2001, 123, 6157-6163; e) C. Martín, F. Molina, E. Alvarez, T. R. Belderrain, Chem. Eur. J. 2011, 17, 1488514895 ; f) Y. Yang, J. Li, B. Du, C. Yuan, B. Liu S. Qin, Chem.Commun. 2015, 51, 6179-6182.

[25] a) M. A. Sierra, M. J. Mancheño, J. C. del Amo, J. Am. Chem. Soc 1998, 120, 6812-6813; b) M. A. Sierra, J. C. del Amo, M. J. Mancheño M. Gómez-Gallego, J. Am. Chem. Soc. 2001, 123, 851-861;c) I. Fernández, M. J. Mancheño, R. Vicente, L. A. López, M. A. Sierra, Chem. Eur. J. 2008, 14, 11222-11230.

[26] a) E. Ihara, M. Fujioka, N. Haida, T. Itoh, K. Inoue, Macromolecules 2005, 38, 2101-2108; b) E. Jellema, A. L. Jongerius, J. N. H. Reek, B. de Bruin. Chem. Soc. Rev. 2010, 39, 1706-1723; c) H. Shimomoto, E. Itoh, T, Itoh, E. Ihara, N. Hoshikawa, N. Hasegawa, Macromolecules 2014, 47, 4169-4177.

[27] The carbene complexes collected in Figures 2, 4, 5, 7 are depicted in order to show the most contributing resonant forms according to the reported structural or spectroscopic data. When this is not clear-cut, the representation chosen by the authors is drawn.

[28] a) D. Bourissou, O. Guerret, F. P. Gabbai, G. Bertrand, Chem. Rev. 2000, 100, 39-91; b) J. Vignolle, X. Cattoën, D. Bourissou, Chem. Rev. 2009, 109, 3333-3384.

[29] M. Bröring, C. D. Brandt, S. Stellwag, Chem. Commun. 2003, 2344 2345.

[30] I. Meana, A. Toledo, A. C. Albéniz, P. Espinet, Chem. Eur. J. 2012, 18, $7658-7661$.

[31] D. Kremzow, G. Seidel, C. W. Lehmann, A. Fürstner. Chem. Eur. J. 2005, 11, 1833 - 1853.

[32] C. -F. Fu, Y. -H. Liu, S. -M. Peng, S. -T. Liu, Tetrahedron, 2010, 66, 2119-2122.

[33] a) M. Wada, Y. Koyama, K. Sameshima, J. Organomet. Chem. 1981, 209, 115-121; b) M. Wada, Y. Koyama, J. Organomet. Chem. 1980 201, $477-491$

[34] a) B. Crociani, M. Nicolini, T. Boschi, J. Organomet. Chem. 1971, 33, C81-C83; b) B. Crociani, R. L. Richards, J. Organomet. Chem. 1978 $154,65-78$. 
[35] V. Lavallo, Y. Canac, C. Präsang, B. Donnadieu, G. Bertrand. Angew. Chem. Int. Ed. 2005, 44, 5705-5709.

[36] a) W. A. Herrmann, Angew.Chem.Int.Ed. 2002, 41, 1290-1309; b) E. A B. Kantchev, C. J. O'Brien, M. G. Organ, Angew. Chem. Int. Ed. 2007, 46, 2768-2813; c) N. Marion, S. P. Nolan, Acc. Chem. Res. 2008, 41 1440-1449 ; d) S. Würtz, F. Glorius, Acc. Chem. Res. 2008, 41, 15231533; e) F. E. Hahn, M. C. Jahnke, Angew. Chem. Int. Ed. 2008, 47, 3122-3172; f) S. Díez-González, N. Marion, S. P. Nolan, Chem. Rev. 2009, 109, 3612-3676; g) P. de Frémont, N. Marion, S. P. Nolan, Coord. Chem. Rev. 2009, 253, 862-892; h) G. C. Fortman, S. P. Nolan, Chem. Soc. Rev. 2011, 40, 5151-5169 ; i) A. T. Normand, K. J. Cavell in N-Heterocyclic Carbenes (Ed.: S. Díez-González), RSC Publishing, Cambridge, 2011, chap. 9; j) C. Valente, S. Çalimsiz, K. H. Hoi, B. Mallik, M. Sayah, M. G. Organ, Angew. Chem. Int. Ed. 2012, 51, 3314 3332; k) D. J. Nelson, S. P. Nolan, Chem. Soc. Rev., 2013, 42, 6723 6753: I) E. Levin, E. Ivry, C. E. Diesen-druck, N. G. Lemcoff, Chem. Rev. 2015, 115, 4607-4692.

[37] a) R. H. Crabtree, Coord. Chem. Rev. 2013, 257, 755-766; b) M. Albretch, Adv. Organomet. Chem. 2014, 62, 111-158.

[38] Cambridge Structural Database System (CSD System, version 5.39, 2018). Cambridge Crystallographic Data Centre, 12 Union Road Cambridge CB2 1EZ, UK.

[39] A. C. Albéniz, P. Espinet, R. Manrique, A. Pérez-Mateo, Angew. Chem. Int. Ed. 2002, 41, 2363-2366.

[40] A. C. Albéniz, P. Espinet, R. Manrique, A. Pérez-Mateo, Chem. Eur. J. 2005, 11, 1565-1573.

[41] A. C. Albéniz, P. Espinet, A. Pérez-Mateo, A. Nova, G. Ujaque, Organometallics 2006, 25, 1293-1297.

[42] H. Lebel, M. K. Janes, A. B. Charette, S. P. Nolan, J. Am. Chem. Soc. 2004, 126, 5046-5047.

[43] W. A. Herrmann, K. Öfele, S. K. Schneider, E. Herdtweck, S. D. Hoffmann. Angew. Chem. Int. Ed. 2006, 45, 3859 -3862.

[44] a) W. A. Herrmann, K. Öfele, C. Taubmann, E. Herdtweck, S. D. Hoffmann. J. Organomet. Chem. 2007, 692, 3846-3854; b) D. F. Wass, M. F. Haddow, T. W. Hey, A. G. Orpen, C. A. Russell, R. L. Wingad, M. Green, Chem. Commun. 2007, 2704-2706.

[45] G. Kuchenbeiser, B. Donnadieu, G. Bertrand. J. Organomet. Chem. 2008, 693, 899-904.

[46] R. D. Wilson, Y. Kamitori, H. Ogoshi, Z. -I. Yoshida, J. A. Ibers. J. Organomet. Chem. 1979, 173, 199-209.

[47] W. H. Meyer, M. Deetlefs, M. Pohlmann, R. Scholz, M. W. Esterhuysen, G. R. Julius, H. G. Raubenheimer, Dalton Trans., 2004, 413-420.

[48] O. Schuster, H. G. Raubenheimer. Inorg. Chem. 2006, 45, 7997-7999.

[49] Y. Han, H. V. Huynh, Chem. Commun. 2007, 1089-1091.

[50] P. Ciu, V. M. Iluc, Chem. Sci. 2015, 6, 7343-7354

[51] a) M. P. López-Alberca, M. J. Mancheño, I. Fernández, M. GómezGallego, M. A. Sierra, R. Torres, Chem. Eur. J. 2009, 15, 3595-3603; b) M. P. López-Alberca, M. J. Mancheño, I. Fernández, M. GómezGallego, M. A. Sierra, R. Torres, Org. Lett. 2007, 9, 1757-1759.

[52] W. Weng, C.-H. Chen, B. M. Foxman, O. V. Ozerov. Organometallics 2007, 26, 3315-3320.

[53] P. Oulié, N. Nebra, N. Saffon, L. Maron, B. Martin-Vaca, D. Bourissou, J. Am. Chem. Soc. 2009, 131, 3493-3498.

[54] Q. Yao, M. Zabawa, J. Woo, C. Zheng, J. Am. Chem. Soc. 2007, 129, 3088-3089.

[55] K. Öfele, E. Tosh, C. Taubmann, and W. A. Herrmann, Chem. Rev. 2009, 109, 3408-3444.

[56] C. C. Comanescu, V. M. Iluc, Organometallics 2014, 33, 6059-6064.

[57] C. C. Comanescu, V. M. Iluc, Organometallics 2015, 34, 4684-4692

[58] a) T. Cantat, N. Mézailles, L. Ricard, Y. Jean, P. Le Floch, Angew. Chem. Int. Ed. 2004, 43, 6382-6385; b) T. Cantat, X. Jacques, L. Ricard, X. F. Le Goff, N. Mézailles, P. Le Floch, Angew. Chem. Int. Ed. 2007, 46, $5947-5950$.
[59] V. H. Gessner, F. Meier, D. Uhrich, M. Kaupp, Chem. Eur. J. 2013, 19, $16729-16739$.

[60] V. H. Gessner, J. Becker, K.-S. Feichtner, Eur. J. Inorg. Chem. 2015, 1841-1859.

[61] P. W. N. M. Van Leeuwen, C. F. Roobeek, R. Huis, J. Organomet. Chem. 1977, 142, 243-247.

[62] J. Cámpora, P. Palma, D. del Río, J. A. López, P. Valerga, Chem. Commun., 2004, 1490-1491.

[63] D. Solé, L. Vallverdú, X. Solans, M. Font-Bardia, J. Bonjoch, Organometallics 2004, 23, 1438-1447.

[64] a) W. -Y. Yu, Y. -T. Tsoi, Z. Zhou, A. S. C. Chan, Org. Lett. 2009, 11, 469-472; b) Y. -T. Tsoi, Z. Zhou, A. S. C. Chan, W. -Y. Yu, Org. Lett. 2010, 12, 4506-4509.

[65] L. R. Falvello, R. Llusar, M. E. Margalejo, R. Navarro, E. P. Urriolabeitia, Organometallics 2003, 22, 1132-1144.

[66] S. Ogoshi, K. Tsutsumi, T. Shinagawa, K. Kaiuchi, H. Kurosawa, Chem. Lett. 1999, 123-124.

[67] a) A. C. Albéniz, P. Espinet, Y. Jeannin, M. Philoche-Levisalles, B. E. Mann, J. Am. Chem. Soc.1990, 112, 6594-6600; b) A. C. Albéniz, P. Espinet, Y. -S. Lin J. Am. Chem. Soc. 1996, 118, 7145-7152; c) A. C Albéniz, P. Espinet, B. Martín-Ruiz, D. Milstein, J. Am. Chem. Soc 2001, 123, 11504-11505; d) P. Espinet, A. C. Albéniz, J. A. Casares, J. M. Martínez-llarduya, Coord. Chem. Rev. 2008, 252, 2180-2208; e) A. C. Albéniz, J. A. Casares, Adv. Organomet. Chem. 2014, 62, 1-110.

[68] A. C. Albéniz, P. Espinet, A. Pérez-Mateo, J. Organomet. Chem. 2010 $695,441-445$

[69] I. Meana, A. C. Albéniz, P. Espinet, Organometallics 2012, 31, 5494-5499.

[70] A. Pérez-Mateo, Thesis Dissertation, Valladolid 2008.

[71] I. Meana, A. C. Albéniz, P. Espinet, Organometallics 2008, 27, 41934198.

[72] A. Danopoulos, N. Tsoureas, J. C. Green, M. B. Hursthouse, Chem. Comm. 2003, 756-757.

[73] a) Y. Xia, S. Qu, Q. Xiao, Z. -X. Wang, P. Qu, L. Chen, Z. Liu, L.Tian, Z. Huang, Y. Zhang, J. Wang, J. Am. Chem. Soc. 2013, 135, 13502-13511; b) F. Ye, S. Qu, L. Zhou, C. Peng, C. Wang, J. Cheng, M. L. Hossain, Y. Liu, Y. Zhang, Z. -X. Wang, J. Wang, J. Am. Chem. Soc. 2015, 137, 4435-4444; c) Y. Yu, Q. Lu, G. Chen, C. Li, X. Huang, Angew. Chem. Int. Ed. 2018, 57, 319-323.

[74] D. S. McGuinness, M. J. Green, K. J. Cavell, B. W. Skelton, A. H. White, J. Organomet. Chem. 1998, 565, 165-178.

[75] D. S. McGuinness, N. Saendig, B. F. Yates, K. J. Cavell, J. Am. Chem. Soc. 2001, 123, 4029- 4040.

[76] D. J. Nielsen, A. M. Magill, B. F. Yates, K. J. Cavell, B. W. Skelton, A. H. White, Chem. Commun. 2002, 2500-2501.

[77] N. Tsoureas, A. A. Danopoulos, A. A. D. Tulloch, M. E. Light, Organometallics 2003, 22, 4750-4758.

[78] a) D. S. McGuinness, K. J. Cavell, Organometallics 2000, 19, 49184920; b) S. Warsink, S. Y. de Boer, L. M. Jongens, C. -F. Fu, S. -T. Liu, J. -T. Chen, M. Lutz, A. L. Spek, C. J. Elsevier, Dalton Trans. 2009, 7080-7086.

[79] A. T. Normand, A. Stasch, L. -L. Ooi, K. J. Cavell, Organometallics 2008, 27, 6507-6520.

[80] W. J. Marshall, V. V. Grushin, Organometallics 2003, 22, 1591-1593.

[81] a) D. S. McGuinness, K. J. Cavell, B. W. Skelton, A. H. White, Organometallics 1999, 18, 1596-1605; b) A. T. Normand, M. S. Nechaev, K. J. Cavell, Chem. Eur. J. 2009, 15, 7063-7073.

[82] K. J. Cavell, A. T. Normand, in N-heterocyclic Carbenes in Transition Metal Catalysis and Organocatalysis (Ed. C. S. J. Cazin), Catalysis by Metal Complexes, Vol. 32, Springer, 2011, pp. 299-314.

[83] K. J. Cavell, D. S. McGuinness, Coord. Chem. Rev. 2004, 248, 671681. 
[84] a) M. S. Viciu, G. A. Grasa, S. P. Nolan, S. P. Organometallics 2001 20, 3607-3612; b) S. Gründemann, M. Albrecht, A. Kovacevic, J. W Faller, R. H. Crabtree, Dalton Trans. 2002, 2163-2167; c) N. D. Clement, K. J. Cavell, C. Jones, C. J. Elsevier, Angew. Chem. Int. Ed. 2004, 43, 1277-1279.
[85] M. V. Baker, D. H. Brown, V. J. Hesler, B. W. Skelton, A. H. White, Organometallics 2007, 26, 250-252. 


\section{Entry for the Table of Contents}

\section{MICROREVIEW}

In contrast to the robust carbenes used as auxiliary ligands in palladium catalysis, other more electrophilic carbene fragments undergo carbenehydrocarbyl coupling in the metal coordination sphere and this has been used in Pd-catalyzed transformations that incorporate a carbene in the final product. A migratory insertion reaction is key, and the observation and study of this step in stoichiometric reactions provides useful information and strong support for mechanistic proposals.

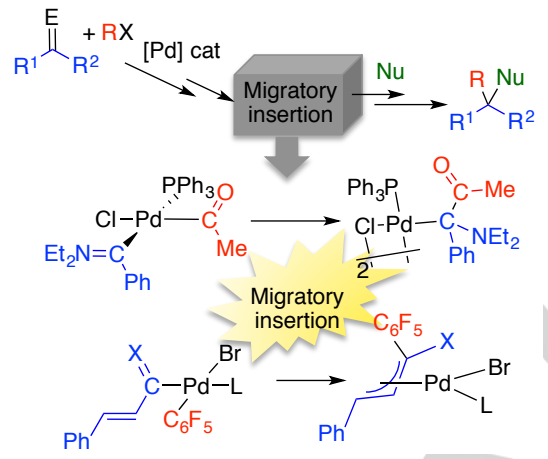

\section{Palladium carbenes}

Ana C. Albéniz*

Page No. - Page No.

Reactive palladium carbenes:

Migratory insertion and other carbene-hydrocarbyl coupling reactions on well-defined systems. 